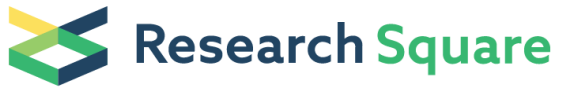 \\ Preprints are preliminary reports that have not undergone peer review. \\ They should not be considered conclusive, used to inform clinical practice, or referenced by the media as validated information.
}

\section{Dental service mix alterations following payment method change}

\section{Reza Emrani}

Tehran University of Medical Sciences, School of Dentistry https://orcid.org/0000-0002-9464-1890

\section{Katayoun Sargeran}

Tehran University of Medical Sciences, Research Center for Caries Prevention, Dentistry Research Institute

\section{Jostein Ivar Grytten}

OsloMet - storbyuniversitetet

Hossein Hessari ( $\nabla$ h-hessar@tums.ac.ir)

https://orcid.org/0000-0003-0412-6893

\section{Research article}

Keywords:

Posted Date: August 28th, 2019

DOI: https://doi.org/10.21203/rs.2.13637/v1

License: (1) (1) This work is licensed under a Creative Commons Attribution 4.0 International License. Read Full License 


\section{Abstract}

Introduction: The number of dental services provided is related to the type of services needed by a population, and treatment decision making by dentists. This descriptive study aimed to compare the dental service mix in two different payment systems salary and fee for service (FFS). Methods: The dental records of a long-established dental clinic in Tehran were reviewed. Treatment performed, during October 2008 and October 2009, by 12 dentists, four dentists worked in both payment method periods, four of them worked only in salary and four of them worked in FFS period. The type of treatment provided was divided into four groups.Practices without treatment (visits, diagnostic radiography, referrals) Practices included preventive treatments (simple restorations, scaling) Practices included aggressive treatments (RCT, extraction, crown) Practices included highly aggressive procedure (surgery) Generalized estimating equation (GEE) was used to analyse data. Results: Preventive dental services (simple restorations, scaling) and practices without treatment (visits, diagnostic radiography, referrals) decreased, and practices included aggressive treatments (RCT, extraction, crown) practices included highly aggressive procedure (surgery) increased from salary to FFS period. The total activities of dentist increased from 1209 in salary group to 1534 in the FFS group. These differences were significant $(p=0.05)$. Conclusions: According to our results, in a salary system, the dentist was more likely to refer and perform preventive treatments, while, in the FFS payment system, the dentists choose more aggressive treatments. Payment method may change dental service mix.

\section{Background}

The knowledge and skills required for dentists have significantly changed. Some issues, such as demographic changes, changing patterns of diseases, new technologies, and economic considerations can affect the combination of dental services provided [1]. Dentists are part of the health system although much of their activities in the provision of care is driven by the "profit principle" to maintain the viability of their practices [2].

The supply of dental services is frequently associated primarily with the time spent by the dentist [3]. The type and frequency of services are referred to as service mix [4]. Factors related to the dental practitioners' practice style and patients are associated with the service mix in dentistry. While several studies have attempted to explain the variation in service patterns, most studies have modelled these factors separately or have included only a limited subset of potential sources of influence on service patterns [5]. Variation in service rates is also related to the dimensions and types of practices [6] [7].

Dentist-related factors include the dentist's practice beliefs, clinical decision-making, and the dentistpatient interaction. Age and the geographic location are also associated with service patterns. Patientlevel factors such as nonemergency visits, dental insurance, and socioeconomic status are related to variations in service rates [6, 8-12]. Economic literature offers theoretical insight into the effectiveness of various remuneration methods in influencing the dentists' behaviour [13-15]. Payment mechanisms have significant effects on clinical decision-making [16] [17]. 
Payment systems have been manipulated in an attempt to achieve policy objectives and as a strategy to improve the quality of care and management, cost containment, health indicators, efficiency, and recruitment to underserved areas. [18] [19]. There are two major categories of payment methods in dentistry: 1- salary or fixed payment 2- fee for service (FFS). Primary care dentists are more likely to accept salaried employment in underserved areas compared to the FFS system, since a fixed income provides more financial security [20]. In a salaried system, the dentist's income depends on the number of hours worked. Dentists are paid a fixed amount of money for a pre-specified amount of hours worked regardless of the number of patients visited or the volume or costs of services provided. This payment method is expected as a result to be associated with reduced activity, increased referrals to specialists and hospitals as dentists concentrate on patients who bring with them the lowest demands $[15,18]$.

FFS and target payments link payment to output and are based on the number and profile of patients. Fee-for-service improves clinical activity (fillings and extractions) and is associated with earlier restoration of caries, more frequent appointments, and less preventive advice given to patients. The most important risk for the patient is that the dentist may prescribe excessive treatments and interventions [21]. Overtreatment occurs among dentists paid by FFS and under treatment may occur in salaried employment where over and under treatment are measured by comparing the prevalence of 'complex' treatments with explicit guidelines for those treatments [22]. The aims of this study were to describe the service-mix of private general practitioners and to investigate the association of service-mix with the method of payment in one dental clinic that had both of payment methods (FFS salary).

\section{Methods}

In this retrospective cohort study, a clinic in the suburbs of Tehran with more than 25 years of work experience and a history of changing management and payment method was approached. The clinic was first established under the salary system, but the owner decided to change the payment system to the FFS and to outsource its management in 2008. This clinic was selected because it experienced a change in the payment method and had a good paper and computerized archive. The head of the clinic consented to the study. This study was conducted in full accordance with the World Medical Association Declaration of Helsinki and was approved by the Ethics Committee of the Tehran University of Medical Sciences, School of Dentistry (code of ethics: 42794260).

The records of four dentists who worked in both periods of payment methods, four dentists who worked only in the FFS method, and four dentists that were only in salaried employment were reviewed. We randomly select patient records from October 1 to 30, 2008 for the salary period and March 1 to 30, 2009 for the FFS period ( $n=75$ records per dentist for each period). The total number of files was 1200 .

In case of incomplete information or ambiguity in records, the records were excluded from the study. Data of specialized services, including orthodontic treatments, implants, and crown lengthening surgery, records of patients under 18 years old, and charity services were excluded. The number of services was then calculated including single visits without treatment, restorations, endodontic treatments, extractions, 
impacted tooth surgery, radiography without treatment, scaling, and patient referrals. Next, dental services were categorized into 4 groups:

1. practices without treatments (visits, diagnostic radiography, referrals)

2. practices included preventive treatments (simple restorations, scaling)

3. practices included aggressive treatments (RCT, extraction, crown)

4. practices included highly aggressive treatments (surgery)

The differences in dental service mix were compared among 12 dentists. Dentists No. 1 to 4 worked in both payment methods, dentists No. 5 to 8 worked only in the salary period, and dentists No.9 to 12 worked only in the FFS period.

First, we compared group $A$ with $B$ and then compared group $C$ with $D$. Next, we compared group $A+C$ with group B+D. Finally, we compared the dentists' activities according to above categories. The activities of 12 dentists were compared as following in Table 1.

Statistical analysis was performed by SPSS software version 21 . To assess the effect of the variables, a generalized estimating equation (GEE) analysis was used. Payment method was considered as a dependent variable and referral, visit, wisdom teeth extraction, molar teeth extraction, frontal teeth extraction, scaling, restoration, endodontic treatment, surgery, crown, and radiography were considered as independent variables.

\section{Results}

In the present study, 1200 records containing dental services provided by 12 dentists in a dental clinic that experienced a change in the payment method were reviewed. Table 2 shows the activities of 4 dentists that worked in both FFS and salary periods. The number of referrals, visits and radiographies without any procedure decreased $(p<0.05)$ after the payment method changed. The number of restorations increased in the salary group, but the difference was marginally not significant $(p=0.0501)$. The number of dental operations and endodontic treatments, posterior teeth extractions increased significantly $(p<0.05)$. The total activities of the FFS group $(=928)$ were higher than the salary group $(=677)$.

Table 3 shows the results of the activities of 8 dentists of whom four worked in the salary and four worked in the FFS period. The number of visits without any procedures, referrals, scaling, and restoration was significantly higher in the FSS period compared to the salary period $(p<0.05)$. The rate of radiography without any following procedure was higher in the salary group, however, the difference was not significant $(p=0.124)$. Extraction of molar teeth, surgery, crown, endodontic therapy was significantly higher in the FFS period $(p<0.05)$. The total activities of the FFS group $(=606)$ were higher compared to the salary group $(=532)$. 
Table 4 shows the aggregation of two previous tables, which confirms their results. The rate of radiography, scaling, referrals and visits was significantly higher in this period $(p<0.05)$. Extracting wisdom and molar teeth and crown, surgery and endodontic treatment increased significantly in FFS period $(p<0.05)$. Restoration increased significantly from salary to FFS. The total activities of dentist increased from 1209 in salary group to 1534 in the FFS group.

Table 5 shows categorized dental services provided by the 12 dentists. Compared to the salary period, preventive services and non-treatment procedures decreased in the FFS period. Table 5 also shows that aggressive and high aggressive treatments increased from the salary period to the FFS period $(p<0.05)$.

\section{Discussion}

The present study was conducted to examine the impact of payment method change on the services provided by dentists through reviewing patient records. The results showed that dentists in a fixed salary system, in which the number of patients does not contribute to a rise in income, tended to carry out lowrisk treatment services, so the rate of patient referrals and visits without any treatment was high in the salary payment system.

On the other hand, there were more preventive services, including scaling and restorations in the fixed salary group. Tooth extraction was common in the fixed salary system, too. Dentists in the FFS system provided more services. The rate of endodontic treatments was much lower in the fixed salary group. It can be assumed that dentists who worked in the salary system preferred extraction in cases where the teeth could be preserved because endodontic treatment is much more time consuming and complicated compared to extraction.

In the FFS system, the dentists carried out more patient care and more aggressive services such as endodontic surgery and third-level preventive services such as dental crowns because of the fact that their income depended on the number of services.

By reviewing patient records, it was found that dentists in the FFS system provided more services to each patient. The findings of this study were similar to the result of a study by Voinea-Griffin et al. conducted in England in 2003. The results of the payment system change in the NHS system from the traditional method to a method with bonus led to more activities of dentists. A first-year assessment of the program revealed that family practitioners accomplished $98 \%$ of the available points for clinical indicators, much higher than the predicted $75 \%$ [23].

Whittaker and Birch found that the same change in the payment method led to some dentists selfselecting 'out' of the NHS in England and a redistribution of care provided under the NHS away from clients with regular visits and towards 'hard to reach' client populations [24].

Similar results were reported by Hemingway et al. (1990) In England. They studied the effect of a change in the payment from salary to payment based on bonuses for 15 physicians in an ambulatory care centre. 
They found that the average number of patient visits per month rose by $12 \%$, and that total charges per month increased by $20 \%$ [25].

in 2015, Stephen Birch found that in the US, patients of dentists paid by FFS had more visits and services than patients of dentists paid by capitation [26].

Our findings were also similar to a study by Marco in Chile. In this study, the activities of dentists in two periods of using and not using the FFS system were studied. Investigation of the 6-year-old patients' files showed that the activities of dentists in tooth extraction increased by $22 \%$ [19].

One of the strengths of this study was to compare the behaviour of dentists in two systems in the same working place. This can be a great help in controlling variables such as the inherent behaviour of individuals. Variables such as change of the working place were also controlled, and the only change was in the payment method.

We also selected one group of dentists that worked in only one period. The findings of the two groups of dentists were similar. Therefore, the payment method can be considered an effective factor in the decision of dentists.

The limitation of our study was the absence of a payment system other than fixed salary and FFS system. In Iran, unlike many other countries, the capitation payment method is not used. If it was possible to compare with other payment systems, it would be more likely to achieve better results. Another limitation was lack of knowledge about the amount of fixed salary. We only knew the type of system, but we did not know the conditions of the contract. It is recommended that a study be conducted to measure the amount of salary in addition to the payment method to determine the impact of the payment method more clearly.

\section{Conclusion}

In conclusion, the service mix of dentists shifts towards preventive services in the salary system and towards more treatments activities in the FFS payment system (diagram 1). This study found that the payment mechanism had significant effects on clinical decision-making, which helps us make sound decisions in different regions to find the most appropriate payment method. The best payment method can be determined according to health plans and in some projects to improve the health programs and balance the costs.

\section{Abbreviations}

FFS: Fee For Service

GEE: Generalized Estimating Equation 


\section{Declarations}

Ethics approval and consent to participate: The authors acquired ethical approval and consent from the head of dental clinics to participate in the study and provide needed data.

Consent to publish: Authors grant BMC a licence to publish the article and identify itself as the original publisher. Authors also grant any third party the right to use the article freely as long as its integrity is maintained and its original authors, citation details and publisher are identified.

Availability of data and materials: All data and photo of patient files are available to be released in case of clear request.

Competing Interests: The authors have no conflict of interest. The authors received no financial support for present study.

Funding: The authors received no funding for present study.

Author's contributions: Reza Emrani and Hossein Hessari conceived of the presented idea. Reza Emrani and Hossein Hessari and Katayoun Sargeran and Jostein Grytteh developed the theory. Reza Emrani referred to dental clinic and gathered patient files data, and entered the data to computer. Reza Emrani and Hossein Hessari verified the analytical methods and performed the statistical analysis. All authors discussed the results and contributed to the final manuscript.

Acknowledgements: The authors would like to acknowledge the staff of the selected dental clinic for their kind cooperation, and Dr. Ahmad Reza Shamshiri for his valuable help in statistical analyses.

\section{References}

1. Light, D.W., Health-care professions, markets and countervailing powers. Handbook of medical sociology, 2010. 6: p. 270-289.

2. Brocklehurst, P. and R. Macey. Skill-mix in preventive dental practice-will it help address need in the future? in BMC oral health. 2015. BioMed Central.

3. Lazar, V.F., A.H. Guay, and T.J. Beazoglou, Economic impact of dental hygienists on solo dental practices. Journal of dental education, 2012. 76(8): p. 1045-1053.

4. Bardey, D., S. Kembou Nzalé, and B. Ventelou, Physicians' incentives to adopt personalized medicine: experimental evidence. Documento CEDE, 2018(2018-59).

5. Shepherd, J., et al., Service: mix of oral and maxillofacial surgeons in Australia and New Zeland. Int J Oral Maxillofacial Surg, 1993. 22(5): p. 310-13.

6. Amarasena, N., et al., Dental knowledge and dental service utilization: A 2-year follow-up study. Community dentistry and oral epidemiology, 2018. 46(4): p. 336-342. 
7. Grembowski, D., P. Milgrom, and L. Flset, Factors influencing variation in dentist service rates. Journal of Public Health Dentistry, 1990. 50(4): p. 244-250.

8. Bailit, H.L. and J. Clive, The development of dental practice profiles. Medical Care, 1981: p. 30-46.

9. Bader, J.D. and D.A. Shugars, Variation in dentists' clinical decisions. Journal of public health dentistry, 1995. 55(3): p. 181-188.

10. Brennan, D., A.J. Spencer, and F. Szuster, Rates of dental service provision between capital city and noncapital locations in Australian private general practice. Australian Journal of Rural Health, 1998. 6(1): p. 12-17.

11. Spencer, A.J. and J.M. Lewis, Service-mix in general dental practice in Australia. Australian dental journal, 1989. 34(1): p. 69-74.

12. Mueller, C.D. and A.C. Monheit, Insurance coverage and the demand for dental care: Results for nonaged white adults. Journal of Health Economics, 1988. 7(1): p. 59-72.

13. Wranik, D.W. and M. Durier-Copp, Physician remuneration methods for family physicians in Canada: expected outcomes and lessons learned. Health Care Analysis, 2010. 18(1): p. 35-59.

14. Grytten, J., Payment systems and incentives in dentistry. Community dentistry and oral epidemiology, 2017. 45(1): p. 1-11.

15. Brocklehurst, P., et al., The effect of different methods of remuneration on the behaviour of primary care dentists. Cochrane Database of Systematic Reviews, 2013(11).

16. Ghoneim, A., How Does Competition Affect the Clinical Decision-Making of Dentists in Ontario? 2018.

17. Shen, J., et al., The effects of payment method on clinical decision-making: physician responses to clinical scenarios. Medical care, 2004: p. 297-302.

18. Gosden, T., et al., Capitation, salary, fee-for-service and mixed systems of payment: effects on the behaviour of primary care physicians. Cochrane Database of Systematic Reviews, 2000(3).

19. Cornejo-Ovalle, M., R. Brignardello-Petersen, and G. Pérez, Pay-for-performance and efficiency in primary oral health care practices in Chile. Revista Clínica de Periodoncia, Implantología y Rehabilitación Oral, 2015. 8(1): p. 60-66.

20. Dan, S. and R. Kruusenberg. Payment systems and incentives in primary care in transition healthcare systems: Implications of recent reforms in Estonia and Romania. in th ECPR conference, Bremen. 2012.

21. Peckham, S. and K. Gousia, GP payment schemes review, October 2014. GP Payment schemes review October 2014, 2014.

22. Carson, S.J. and R. Freeman, Training and fairer payments would increase caries prevention in practice. Evidence-based dentistry, 2015. 16(1): p. 6.

23. Voinea-Griffin, A., et al., Pay-for-performance in dentistry: what we know. Journal for Healthcare Quality, 2010. 32(1): p. 51-58.

24. Whittaker, W. and S. Birch, Provider incentives and access to dental care: evaluating NHS reforms in England. Social Science \& Medicine, 2012. 75(12): p. 2515-2521. 
25. Hemenway, D., et al., Physicians' responses to financial incentives: evidence from a for-profit ambulatory care center. New England journal of medicine, 1990. 322(15): p. 1059-1063.

26. Birch, S. Paying for prevention in clinical practice: aligning provider remuneration with system objectives. in BMC oral health. 2015. BioMed Central.

\section{Tables}

Table 1. Schematic timeline of dental services assessments provided by 12 dentists in a dental clinic in two different payment methods of salary and FFS

\begin{tabular}{|c|c|c|}
\hline & $\begin{array}{l}\text { Salary } \\
\text { period } \\
\text { (Before } \\
\text { 2009) } \\
\end{array}$ & $\begin{array}{l}\text { FFS period } \\
\text { (After } \\
\text { 2009) }\end{array}$ \\
\hline & Group A & Group B \\
\hline \multirow[t]{9}{*}{ Four dentists who worked in both payment periods } & Dentist NO. & Dentist NO. \\
\hline & 1 & 1 \\
\hline & Dentist NO. & Dentist NO. \\
\hline & 2 & 2 \\
\hline & Dentist NO. & Dentist NO. \\
\hline & 3 & 3 \\
\hline & Dentist NO. & Dentist NO. \\
\hline & 4 & 4 \\
\hline & Group C & Group D \\
\hline \multirow{8}{*}{$\begin{array}{l}\text { Eight dentists of whom four worked only in salary period and four } \\
\text { worked in FFS period }\end{array}$} & Dentist NO. & Dentist NO. \\
\hline & 5 & 9 \\
\hline & Dentist NO. & Dentist NO. \\
\hline & 6 & 10 \\
\hline & Dentist NO. & Dentist NO. \\
\hline & & \\
\hline & Dentist NO. & Dentist NO. \\
\hline & 8 & 12 \\
\hline
\end{tabular}


Table 2. Comparison of services provided by 4 dentists working in payment methods of salary and fee-for-services (FFS)

\begin{tabular}{|c|c|c|c|c|c|c|c|c|}
\hline \multirow[t]{2}{*}{ Dental services } & \multirow[t]{2}{*}{ Salary } & \multirow[t]{2}{*}{ FFS } & \multirow[t]{2}{*}{ Difference } & \multicolumn{2}{|c|}{$95 \% \mathrm{Cl}$} & \multirow[t]{2}{*}{ B } & \multirow[t]{2}{*}{ SE } & \multirow[t]{2}{*}{ p-value } \\
\hline & & & & Lower & Upper & & & \\
\hline Radiography & 35 & 11 & -24 & 0.069 & -0.037 & 0.046 & 0.015 & 0.030 \\
\hline Extraction of wisdom tooth & 79 & 103 & 24 & -0.210 & -0.760 & 0.014 & 0.052 & 0.040 \\
\hline Extraction of molars & 108 & 161 & 53 & -0.550 & -0.018 & 0.014 & -0.270 & 0.040 \\
\hline Extraction of frontal tooth & 38 & 41 & 3 & -0.140 & +0.390 & 0.013 & 0.012 & 0.870 \\
\hline Crown & 38 & 130 & 92 & -0.150 & -0.070 & 0.016 & 0.015 & 0.000 \\
\hline Restoration & 170 & 161 & -9 & -0.640 & 0.320 & 0.010 & -0.053 & 0.050 \\
\hline Endodontic therapy & 65 & 198 & 133 & 0.211 & 0.026 & 0.014 & 0.239 & 0.001 \\
\hline Surgery & 3 & 57 & 54 & 0.210 & 0.270 & 0.290 & 0.155 & 0.001 \\
\hline Referral & 46 & 24 & -22 & -0.150 & -0.030 & 0.040 & -0.640 & 0.001 \\
\hline Scaling & 66 & 41 & -25 & -0.190 & 0.610 & 0.059 & 0.144 & 0.001 \\
\hline Visit without any following procedure & 29 & 1 & -28 & 0.150 & 0.349 & 0.036 & -0.329 & 0.001 \\
\hline Total & 677 & 928 & & & & & & \\
\hline
\end{tabular}

Statistical analysis: Generalized Estimating Equation (GEE) model was applied. Model: Intercept. Dependent Variable: payment method. Independent variables: dental services. P-value $<0.05$ was considered as significant.

Table 3. Comparison of services provided by 8 dentists who worked in either the salary method or fee-for-services (FFS)

\begin{tabular}{lcccccccc}
\hline & \multicolumn{1}{c}{$90 \% \mathrm{Cl}$} \\
Dental services & SALARY & FFS & Difference & Lower & Upper & B & SE & p-value \\
\hline Radiography & 11 & 8 & +3 & -0.07 & 0.400 & 0.015 & 0.045 & 0.124 \\
Extraction of wisdom tooth & 74 & 99 & +25 & -0.21 & 0.780 & 0.050 & 0.014 & 0.001 \\
\hline Extraction of molars & 83 & 98 & -15 & -0.35 & 0.060 & -0.27 & 0.014 & 0.049 \\
\hline Extraction of frontal teeth & 22 & 23 & +1 & 0.14 & 0.390 & 0.012 & 0.013 & 0.789 \\
\hline Crown & 19 & 32 & +13 & -0.19 & -0.09 & 0.150 & 0.012 & 0.001 \\
\hline Restoration & 130 & 82 & -48 & -0.74 & -0.32 & 0.053 & 0.010 & 0.001 \\
\hline Endodontic therapy & 64 & 193 & +129 & 0.20 & .0255 & 0.219 & 0.014 & 0.001 \\
\hline Surgery & 7 & 20 & +13 & 0.210 & 0.270 & 0.155 & 0.290 & 0.001 \\
\hline Referral & 43 & 19 & -24 & -0.13 & -0.06 & 0.640 & 0.024 & 0.001 \\
\hline Scaling & 65 & 24 & -41 & -0.20 & 0.057 & 0.134 & 0.059 & 0.002 \\
\hline Visit without any following procedure & 14 & 8 & -6 & 0.15 & 2.490 & 0.304 & 0.0313 & 0.020 \\
\hline Total & 532 & 606 & -6 & & & - & - & - \\
\hline
\end{tabular}

Statistical analysis: Generalized Estimating Equation (GEE) model was applied. Model: Intercept. Dependent Variable: payment method. Independent variables: dental services. P-value<0.05 was considered as significant. 
Table 4. Comparison of services provided by 12 dentists who worked in both payment methods of salary and fee-for-services (FFS)

\begin{tabular}{lllllllll}
\hline & & \multicolumn{7}{c}{$95 \% \mathrm{Cl}$} \\
Dental services & SALARY & FFS & Difference & Lower & Upper & B & SE & p-value \\
\hline Radiography & $46(3.7)$ & $19(1.2)$ & -27 & -0.07 & -0.03 & .015 & 0.047 & 0.050 \\
Extraction of wisdom tooth & $153(12.2)$ & $202(15.9)$ & 49 & -0.21 & -0.78 & .050 & 0.014 & 0.031 \\
\hline Extraction of molars & $191(15.3)$ & $259(16)$ & 68 & -0.55 & 0.01 & -0.27 & 0.014 & 0.049 \\
\hline Extraction of frontal teeth & $60(5)$ & $64(4)$ & 4 & -0.14 & 0.39 & .012 & 0.013 & 0.974 \\
\hline Crown & $57(4.9)$ & $162(10.2)$ & 105 & -0.16 & -0.08 & .015 & 0.016 & 0.000 \\
\hline Restoration & $300(24)$ & $243(14.9)$ & -57 & -0.74 & -0.32 & -0.05 & 0.010 & 0.030 \\
\hline Endodontic therapy & $129(10.3)$ & $391(24.4)$ & 262 & 0.21 & 0.02 & 0.239 & 0.014 & 0.000 \\
\hline Surgery & $10(1.2)$ & $77(4.9)$ & 67 & 0.21 & 0.27 & 0.155 & 0.290 & 0.000 \\
\hline Referral & $89(7.6)$ & $43(2.6)$ & -46 & -0.14 & -0.05 & -0.64 & 0.040 & 0.000 \\
\hline Scaling & $131(12.4)$ & $65(5)$ & -66 & -0.18 & 0.06 & 0.144 & 0.059 & 0.020 \\
\hline Visit without any following procedure & $43(3.4)$ & $9(0.9)$ & 34 & 0.15 & 2.49 & -0.30 & .0368 & 0.000 \\
\hline Total & 1209 & 1534 & 325 & & - & - & - & - \\
\hline
\end{tabular}

Statistical analysis: Generalized Estimating Equation (GEE) model was applied. Model: Intercept. Dependent Variable: payment method. Independent variables: dental services. P-value $<0.05$ was considered as significant.

Table 5. Combination of service mix according to the type of treatments among 12 dentists in both fees-for-services (FFS) ( $n=600$ patient files) and salary ( $n=600$ files) periods

\section{Salary FFS Difference $95 \% \mathrm{Cl}$}

Non - treatment procedures

(visit, refer, radiography)

Preventive services

(restoration, scaling)

Aggressive treatments

(endodontic, extraction, crown)

\section{High-Aggressive treatments}

(surgery)

\section{Lower Upper}

$\begin{array}{cccccccc}184 & 72 & -112 & 0.15 & 2.46 & 0.150 & 0.190 & 0.01 \\ 449 & 291 & -158 & 0.16 & 2.39 & 0.016 & 0.017 & 0.02 \\ 561 & 1094 & +533 & -0.17 & -0.09 & 0.042 & 0.010 & 0.04 \\ 15 & 77 & +62 & 0.15 & 2.19 & 0.20 & 0.014 & 0.00\end{array}$

Statistical analysis: Generalized Estimating Equation (GEE) model was applied. Model: Intercept. Dependent Variable: payment method. Independent variables: Categorized dental services. P-value<0.05 was considered as significant.

\section{Figures}


Diagram 1. Shifts of dental service mix following payment method change

\begin{tabular}{|l|l|l|l|}
\hline & References & Salary & FFS \\
\hline Preventive services & $22,21,20$ & \\
\hline Aggressive treatments & 18,19 & \\
\hline Emergency treatment services & 17 & \\
\hline Referral rate & $18,15,16,10$ & \\
\hline Visits without any following procedure & 26,27 & \\
\hline
\end{tabular}

Figure 1

Shifts of dental service mix following payment method change 